Original Article

\title{
DEVELOPMENT OF NANOPARTICLES SUSPENSION FOR PAEDIATRIC DRUG ADMINISTRATION
}

\author{
K. K. RAJULA ${ }^{*}$, JISHA MOHANAN ${ }^{1}$ \\ ${ }^{1}$ College of Pharmaceutical Sciences, Govt. Medical College, Calicut 673008, India \\ "Email: julirajula@gmail.com
}

Received: 05 Nov 2021, Revised and Accepted: 16 Dec 2021

\begin{abstract}
Objective: Enalapril maleate (EM) is an angiotensin-converting enzyme (ACE) inhibitor. It is generally prescribed for the treatment of hypertension, heart failure and chronic kidney diseases in adults and children. EM $2.5 \mathrm{mg}, 5 \mathrm{mg}, 10 \mathrm{mg}$ and $20 \mathrm{mg}$ tablets and EM injection $1.25 \mathrm{mg} / \mathrm{ml}$ are currently available in the market. But a liquid paediatric formulation of this medicine is not currently available. Also, it is a BCS class III drug, having a bioavailability of approximately $60 \%$. The present study proposes a new strategy for improvement of drug bioavailability and taste masking: EM nanoencapsulation within polymeric nanoparticles suspensions prepared with Eudragit RS100 (ERS100) as polymer and Tween 80 as a stabilizer, aiming at obtaining a liquid dosage form suitable for paediatric administration.
\end{abstract}

Methods: Nanoprecipitation method used for the preparation of nanoparticles suspension. The preparations were evaluated for drug content, entrapment efficiency, particle size, zeta potential, polydispersity index, pH, viscosity and in vitro drug release. Based on the entrapment efficiency, viscosity and in vitro drug release the optimized formulation was selected. Optimized formulation evaluated for taste, ex vivo intestinal permeation, differential scanning calorimetry, scanning electron microscopy and release kinetic studies.

Results: The optimized nanoparticle formulation F8 having drug to polymer ratio of 1:100 showed satisfactory drug content (95.1\%), entrapment efficiency (77.71\%), particle size (198.47 $\mathrm{nm}), \mathrm{pH}(6.36)$, viscosity $\left(2.9 \times \mathbf{1 0}^{-3} \mathrm{~Pa} \cdot \mathrm{s}\right)$ and $81.2 \%$ drug release after $12 \mathrm{~h}$. The formulation has tastemasking properties and shows $84.6 \%$ drug permeation through the goat intestine within $12 \mathrm{~h}$.

Conclusion: The prepared nanoparticles suspension of Enalapril maleate was found to be an effective liquid pharmaceutical dosage form for paediatric administration with taste-masking properties.

Keywords: Enalapril maleate, Nanoparticles suspension, Paediatric formulation, Taste masking, Eudragit RS 100, Tween 80

(C) 2022 The Authors. Published by Innovare Academic Sciences Pvt Ltd. This is an open access article under the CC BY license (https://creativecommons.org/licenses/by/4.0/) DOI: https://dx.doi.org/10.22159/ijpps.2022v14i2.43529. Journal homepage: https://innovareacademics.in/journals/index.php/ijpps.

\section{INTRODUCTION}

The pharmaceutical formulation of paediatric medicines is one of the most challenging and critical areas in drug development. The drug formulations used in paediatric pharmacotherapy should be suited to their age, size, physiologic condition, and treatment requirements. Such paediatric medicines are important to achieve safe and accurate dose administration, reducing the risk of medication errors, enhancing compliance, and improving therapeutic outcomes in children [1].

Enalapril maleate (EM) is an angiotensin-converting enzyme (ACE) inhibitor. It is an ethyl ester prodrug, and pharmacological effects are mediated by the active metabolite, enalaprilat. The main effect of enalaprilat is the inhibition of ACE, a key component in the reninangiotensin-aldosterone system. It is generally prescribed for the treatment of hypertension, heart failure and chronic kidney diseases in adults and children. EM $2.5 \mathrm{mg}, 5 \mathrm{mg}, 10 \mathrm{mg}$ and $20 \mathrm{mg}$ tablets and EM injection $1.25 \mathrm{mg} / \mathrm{ml}$ are currently available in the market. But a liquid paediatric formulation of this medicine is not currently available. So, in our medical colleges, there is a dilution unit where the tablets were powdered and diluted with lactose to produce an extemporaneous powder formulation to scale down its dose which is given to the paediatric patients. It is necessary to develop paediatric friendly formulations to achieve the right therapeutic concentration, avoid side effects, improve palatability and enhance patient compliance $[2,3]$.

Children, as a specific group of patients, have additional requirements for oral administration. EM is a bitter-tasting drug; therefore, a taste-masking approach is to make the formulation suitable for paediatric administration. Also, it is a BCS class III drug, so it has high solubility and low permeability and has a bioavailability of approximately $60 \%[4,5]$.
Nanoparticles suspension have been introduced as a technique for the improvement of the bioavailability of drugs [6, 7]. Nanoparticles are colloidal particles ranging from 10 to $1000 \mathrm{~nm}$, in which the active principles (drug or biologically active material) are dissolved, entrapped. With the development of nanotechnology, it is now possible to produce drug nanoparticles that can be utilized in a variety of innovative ways $[8,9,10]$. The Nanoprecipitation technique (or solvent displacement method) was used for the preparation of nanoparticles suspension $[7,11]$. It is a straightforward technique, rapid and easy to perform. Thus, the study aimed to develop EMloaded nanoparticles suspension for paediatric administration with taste-masking properties.

\section{MATERIALS AND METHODS}

Enalapril maleate was purchased from Yarrow Chem Labs, Mumbai, Eudragit RS100 (Sigma Aldrich, Bangalore), Tween 80 (Sigma Aldrich, Bangalore). All the reagents used in this study were of analytical grade.

Preparation of enalapril maleate loaded nanoparticles
suspension suspension

Enalapril maleate loaded nanoparticles suspensions were prepared by the nanoprecipitation method. Accurately weighed the required quantities of EM and ERS100 as per table 1, and dissolved in acetone (organic phase). The aqueous phase was prepared by dissolving the required quantity of Tween 80 in water. The organic phase was magnetically stirred atc $40 \mathrm{r} 10 \mathrm{~min}$. Then organic phase was injected into the aqueous phase under magnetic stirring. The stirring continued for 1 hour at $1200 \mathrm{rpm}$, $40^{\circ} \mathrm{C}$. Organic solvent and part of water evaporated. Then sweetening (glycerol) and flavoring (strawberry) agents were added to get the finished product $[6,7,12]$. 
Table 1: Composition of nanoparticles suspension

\begin{tabular}{|c|c|c|c|c|c|c|}
\hline Formulation code & EM: ERS100 & EM (mg) & ERS100 (mg) & Tween 80 (\%) & Glycerol (\%) & Strawberry flavor \\
\hline F1 & $1: 50$ & 5 & 250 & 0.4 & 3 & q. $s$ \\
\hline F2 & $1: 50$ & 5 & 250 & 0.8 & 3 & q. $s$ \\
\hline F3 & $1: 50$ & 5 & 250 & 1.2 & 3 & q. $s$ \\
\hline $\mathrm{F} 4$ & $1: 75$ & 5 & 375 & 0.4 & 3 & q. $s$ \\
\hline F5 & $1: 75$ & 5 & 375 & 0.8 & 3 & q. $s$ \\
\hline F6 & $1: 75$ & 5 & 375 & 1.2 & 3 & q. $s$ \\
\hline F7 & $1: 100$ & 5 & 500 & 0.4 & 3 & q. $s$ \\
\hline F8 & $1: 100$ & 5 & 500 & 0.8 & 3 & q. $s$ \\
\hline F9 & $1: 100$ & 5 & 500 & 1.2 & 3 & g. $s$ \\
\hline
\end{tabular}

Evaluation of enalapril maleate loaded nanoparticles suspension

\section{Drug content}

Accurately measured $1 \mathrm{ml}$ of nanoparticles suspension and taken in a $10 \mathrm{ml}$ volumetric flask and made up to the volume with phosphate buffer pH 6.8. The amount of the drug was determined spectrophotometrically at $211 \mathrm{~nm}$ after suitable dilutions with phosphate buffer pH $6.8[13,14]$.

\section{Entrapment efficiency}

The freshly prepared nanoparticles suspension $(1 \mathrm{ml})$ was centrifuged at $5000 \mathrm{rpm}$ for $20 \mathrm{~min}$. The supernatant was collected. The amount of unentrapped drug was determined by taking the absorbance of the ultrafiltrate UV spectrophotometrically at $211 \mathrm{~nm}$ after suitable dilutions with phosphate buffer $\mathrm{pH} 6.8$ [7].

$\%$ Entrapment efficiency was determined by using the formula:

$$
\% \text { Entrapment efficiency }=\frac{\text { Total drug }- \text { Free drug }}{\text { Total drug }} \times 100
$$

\section{Particle size, polydispersity index, and zeta potential}

Particle size, Polydispersity index and Zeta potential were measured by dynamic laser scattering or photon correlation spectroscopy using a Malvern Zeta sizer Nano ZS (Malvern Instruments, Malvern, UK). $2 \mathrm{ml}$ of the nanoparticles suspension vortexed and/or sonicated for a few minutes at $25^{\circ} \mathrm{C}$ and a scattering angle of $90^{\circ}$. To determine the zeta potential, nanoparticles suspension was taken in disposable zeta cells and measured by Malvern Zeta sizer. Each sample was measured in triplicate [15].

\section{Determination of $\mathrm{pH}$}

The $\mathrm{pH}$ of formulations was determined by using a digital $\mathrm{pH}$ meter. $5 \mathrm{ml}$ of the formulation was taken, then the electrode was dipped and constant reading was noted. The measurement of $\mathrm{pH}$ was carried out in triplicate.

\section{Determination of viscosity}

The viscosity of different formulations was determined by repeated trial and error method using a Brookfield viscometer (LV DV PrimeI) with spindle number 21 . The viscosity values were measured at room temperature $\left(25^{\circ} \mathrm{C}\right)$.

\section{In vitro drug release study}

The in vitro drug release studies of Enalapril maleate loaded nanoparticles suspension were carried out using the dialysis membrane diffusion technique.

The dialysis membrane was hydrated with distilled water for $12 \mathrm{~h}$ before the study. $5 \mathrm{ml}$ nanoparticles suspension was filled in the dialysis bag bound to a diffusion tube and it was immersed in a beaker containing $50 \mathrm{ml}$ of release medium $(0.1 \mathrm{~N} \mathrm{HCl} \mathrm{pH} 1.2$ buffer for first 1 hour and then phosphate buffer $\mathrm{pH} 6.8$ up to $12 \mathrm{~h}$ ). The temperature of the diffusion medium was thermostatically controlled at $37^{\circ} \mathrm{C}$ and was kept under continuous magnetic stirring at $100 \mathrm{rpm}$. Then at predetermined time intervals $(0,1,2,3,4,5,6$, $7,8,9,10,11$ and $12 \mathrm{~h}$ ) $5 \mathrm{ml}$ of sample was withdrawn and replaced by a fresh medium. The samples were analyzed for drug content by UV visible spectrophotometer at $211 \mathrm{~nm}$ [6].

\section{Optimization of formulations}

The entrapment efficiency, viscosity and in vitro drug release data of all the formulations were compared. The formulation with favourable properties was selected to proceed with further evaluations.

\section{Evaluation of optimized formulation}

\section{Taste evaluation}

The taste of the selected formulation was evaluated by the spectrophotometric method. In this method, the release of the drug into phosphate buffer $\mathrm{pH} 6.8$ was determined to predict the release of the drug into the salivary fluid in humans $[4,16]$.

$2 \mathrm{ml}$ of the nanoparticles suspension was placed in $10 \mathrm{ml}$ phosphate buffer $\mathrm{pH} 6.8$ and stirred at $37 \pm 0.5{ }^{\circ} \mathrm{C}$ at $100 \mathrm{rpm}$ on an electromagnetic stirrer for $60 \mathrm{~s}$. The supernatant was isolated via filtration and the absorption was measured spectrophotometrically at $211 \mathrm{~nm}$. The concentration of the sample was compared with the threshold bitterness concentration of pure Enalapril maleate $(0.107$ $\mathrm{mmol} / \mathrm{l}$ or $28 \mu \mathrm{g} / \mathrm{ml}$ ) [17]. If the concentration is below the threshold concentration, it may be concluded that the bitter taste would be masked in vivo.

\section{Ex vivo permeation study}

Ex vivo permeation study was carried out by non-everted intestinal sac method using freshly excised goat intestine. 6-7 cm long small intestine of the goat was separated and washed with $\mathrm{pH} 6.8$ phosphate buffer to remove any mucous and lumen contents. The segment was tied at one end with a cotton thread and $5 \mathrm{ml}$ of nanoparticles suspension filled in the sac. Then another end of the intestine was tied. The intestinal sac was placed in a beaker containing $100 \mathrm{ml}$ phosphate buffer $\mathrm{pH} 6.8$ (as the serosal solution) maintained at $37 \pm 0.5{ }^{\circ} \mathrm{C}$, kept under continuous magnetic stirring at $100 \mathrm{rpm}$ and constantly aerated with oxygen (30-50 bubbles/min) using a laboratory aerator. Then at predetermined time intervals $(0$, $1,2,3,4,5,6,7,8,9,10,11$ and $12 \mathrm{~h}) 5 \mathrm{ml}$ of sample was withdrawn from outside the sac (serosal solution) and replaced by fresh medium. The serosal concentration of the Enalapril maleate was analyzed spectrophotometrically at $211 \mathrm{~nm}$ [18-20].

\section{Differential scanning calorimetry (DSC)}

The physical state of the drug entrapped in the nanoparticles was characterized by differential scanning calorimetry (DSC) using model Q200 equipped with an automated computer-controlled refrigerated cooling system. A sample of drug and nanoparticle formulation was placed in a standard aluminium pan with a lid. The heating rate was set to $10^{\circ} \mathrm{C} / \mathrm{min}$ between $30-300^{\circ} \mathrm{C}$ and the curves were plotted.

\section{Scanning electron microscopy (SEM)}

The morphology of Enalapril maleate loaded nanoparticles suspension was characterized by using a scanning electron microscope. For liquid samples, a piece of aluminium foil was spread over a glass plate and a drop of the sample was placed on to the centre of the foil, which was then air-dried overnight. The sample was coated with gold and examined under the electron microscope.

\section{In vitro drug release kinetic study}

To examine the drug release kinetics and to evaluate the release mechanism of the drug, the results of in vitro drug release profiles 
obtained for the optimized formulation were fitted into zero-order, first-order, Higuchi and Korsmeyer-Peppas model. The model with the highest regression coefficient $\left(\mathrm{R}^{2}\right)$ was considered to be the best fit model $[21,22]$.

\section{RESULTS AND DISCUSSION}

Preparation of Enalapril maleate loaded nanoparticles suspension

Enalapril maleate loaded nanoparticles suspension were successfully prepared by the Nanoprecipitation technique. The method was simple, reproducible, fast, economic and one of the easiest procedures for the preparation of nanoparticles. The nanoparticles suspensions were spontaneously formed when the organic phase (acetone) containing Eudragit RS100 and Enalapril maleate was injected into stirred aqueous surfactant solution (Tween 80), resulting in a colloidal suspension. Instantaneous formation of a colloidal suspension occurred as a result of the polymer deposition on the interface between the organic phase and water when partially water-miscible organic solvent (acetone) diffused out quickly into the aqueous phase from each transient particle intermediate.

Various formulations of EM (F1-F9) were prepared using ERS100 at different ratios $(1: 50,1: 75$ and1:100) and stabilizer (Tween 80) at different concentrations $(0.4 \%, 0.8 \%$ and $1.2 \%)$.
Evaluation of enalapril maleate loaded nanoparticles suspension

\section{Drug content}

The drug content of all the formulations was found to be in the range of $92.0 \%$ to $96.2 \%$ (table 2).

\section{Entrapment efficiency}

The entrapment efficiency of all the formulations was found to be in the range of 39.53\%-79.84\% (table 2). The entrapment efficiency of EM-loaded nanoparticles showed a positive relationship with polymer concentration. This is because, increase in polymer concentration in the organic phase increases drug entrapment due to an increase in organic phase viscosity, which increases the diffusional resistance to drug molecules from the organic phase to the aqueous phase, thereby entrapping more drugs in the polymeric nanoparticles $[23,24]$.

There is also a slight decrease in the entrapment efficiency with an increase in stabilizer concentration (Tween 80 ). That was probably caused by the decrease in particle size. Moreover, with the increase of Tween 80 concentration in the aqueous phase, more molecules of drugs may partition out rapidly from the organic phase into the aqueous phase during the emulsification procedure and fewer drug molecules remained in emulsion droplets to interact with polymer molecules, hence decreasing the entrapment efficiencies [24].

Table 2: Drug content and entrapment efficiency of nanoparticles suspensions

\begin{tabular}{lll}
\hline Formulation code & \% Drug content $^{*}$ & \% Entrapment efficiency $^{*}$ \\
\hline F1 & $93.9 \pm 0.08$ & $45.73 \pm 0.21$ \\
F2 & $92.0 \pm 0.03$ & $42.30 \pm 0.05$ \\
F3 & $96.2 \pm 0.12$ & $39.53 \pm 0.08$ \\
F4 & $95.2 \pm 0.03$ & $66.53 \pm 0.15$ \\
F5 & $94.4 \pm 0.13$ & $63.35 \pm 0.23$ \\
F6 & $92.5 \pm 0.25$ & $59.13 \pm 0.04$ \\
F7 & $95.3 \pm 0.06$ & $79.84 \pm 0.08$ \\
F8 & $95.1 \pm 0.02$ & $77.71 \pm 0.16$ \\
F9 & $93.0 \pm 0.14$ & $73.12 \pm 0.03$ \\
\hline
\end{tabular}

$*(n=3$, mean \pm standard deviation (SD))

\section{Particle size, polydispersity index and zeta potential}

The particle size, zeta potential and polydispersity index (PDI) of Enalapril maleate loaded nanoparticles suspensions were listed in table 3.

The particle size of nanoparticles in the suspension ranged between 124.48-211.81 nm (fig. 1). The particle size of the polymeric nanoparticles increased with increasing polymer concentration in the organic phase. This is because increasing Eudragit RS100 concentration led to an increase in the viscosity of the organic phase. A more viscous organic phase provides a higher mass transfer resistance to the diffusion of the polymer-solvent phase into the external aqueous phase and larger nanoparticles are formed. A decrease in viscosity of the organic phase increases the distribution effect of the polymer-solvent phase into the external phase leading to the formation of smaller nanoparticles $[15,24]$.

There is a small reduction in the particle size with increasing concentration of stabilizer (Tween 80). This is because, at high concentration, more Tween 80 could be oriented at organic solvent/water interface to reduce efficiently the interfacial tension, which resulted in a significant increase in the net shear stress. So, reduction in particle size could be obtained by optimum interfacial stabilization by the hydrophilic surfactant Tween 80 , which has a high HLB value of $15[23,25]$.

Table 3: Particle size, polydispersity index and zeta potential of nanoparticles suspensions

\begin{tabular}{|c|c|c|c|}
\hline Formulation & Mean particle size $(\mathrm{nm})^{*}$ & PDI & $\mathrm{ZP}(\mathrm{mV})$ \\
\hline F1 & 124.48 & 0.186 & 21.65 \\
\hline $\mathrm{F} 4$ & 162.82 & 0.201 & 28.43 \\
\hline F7 & 211.81 & 0.218 & 40.58 \\
\hline F8 & 198.47 & 0.191 & 34.12 \\
\hline F9 & 191.57 & 0.214 & 32.37 \\
\hline
\end{tabular}

${ }^{*} \mathrm{n}=3$

The zeta potential was positive for all formulations (fig. 2) due to the cationic nature of the polymer Eudragit RS100 due to the quaternary ammonium groups on the polymer surface. The increase in the concentration of Eudragit RS100 raised the zeta potential because less Tween 80 is covering the nanoparticle surface and shielding the charge of the polymer $[9,39]$. So, there is a slight decrease in the zeta potential when the concentration of
Tween 80 increases. This is because Tween 80 is covering the nanoparticle surface and shields the charge on the nanoparticle surface [15].

PDI is another factor that represents the dispersion homogeneity, the range for the PDI is from 0 to 1 . The PDI for all formulations was greater than 0 , which indicates a relative homogenous dispersion. 


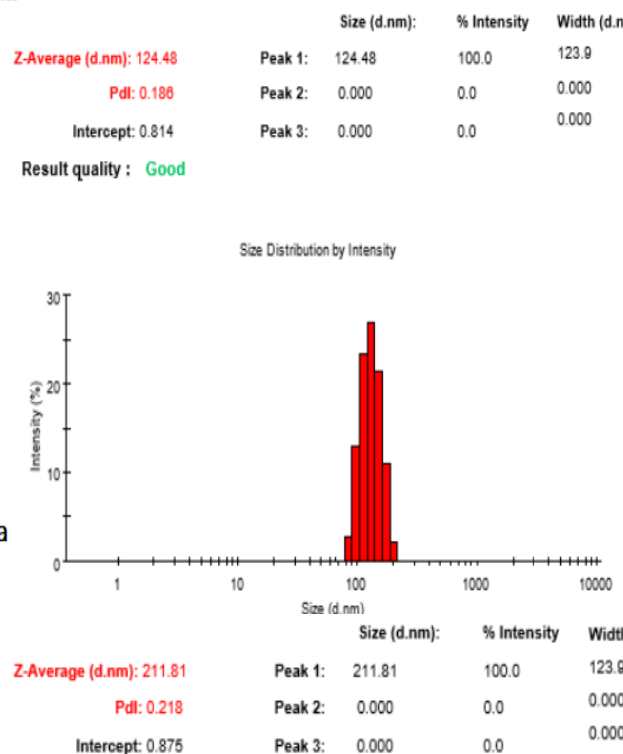

Result quality : Good

Sice Distribution by Intensity
Z-Average (d.nm): 162.82
Pdl: 0.201
Intercept: 0.874
Result quality: Good
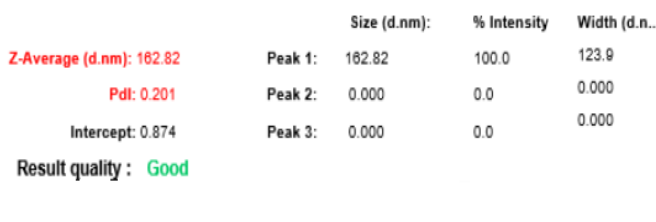

Sce Distribution by Intensity
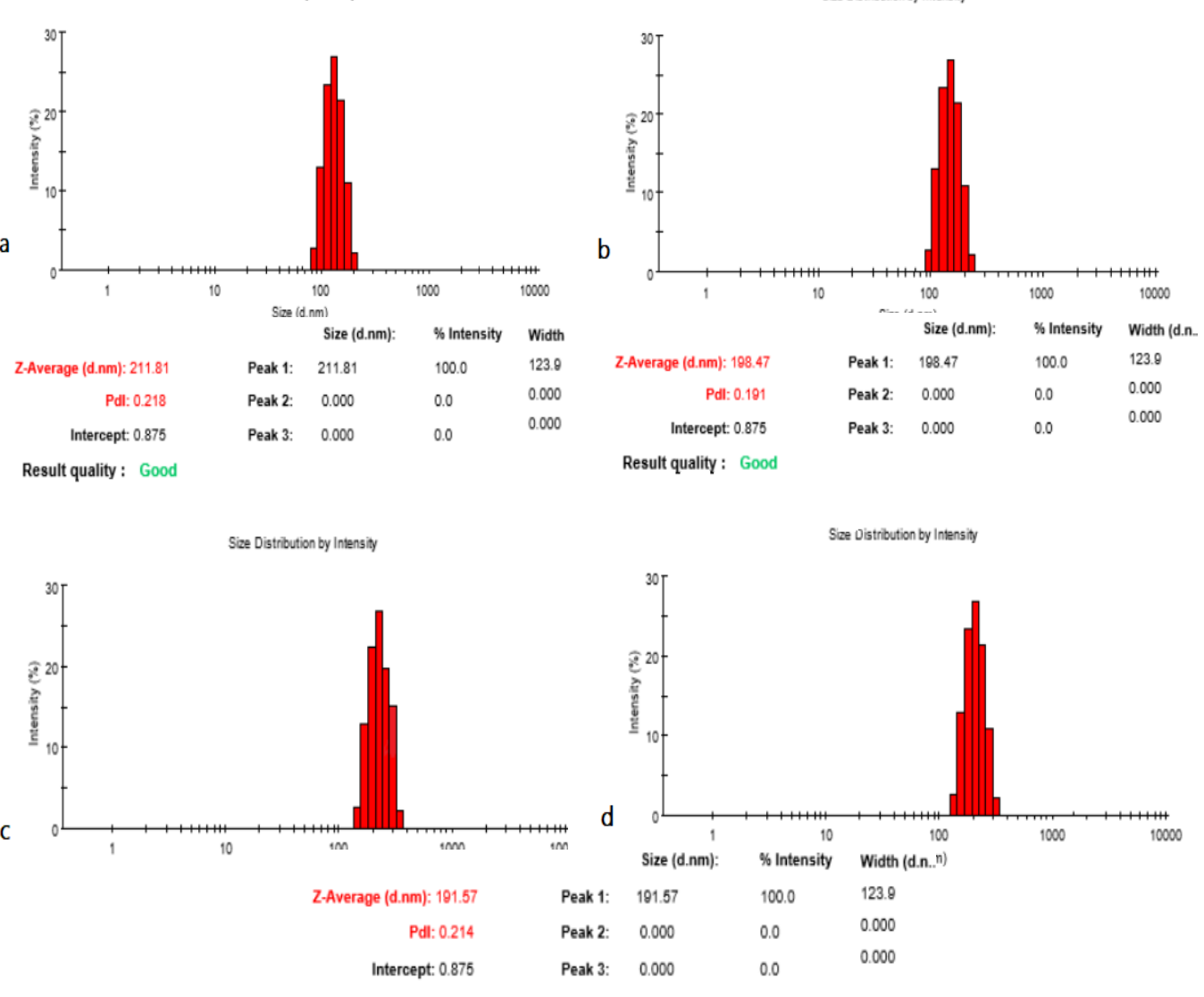

Result quality : Good

Size Distribution by Inlensity

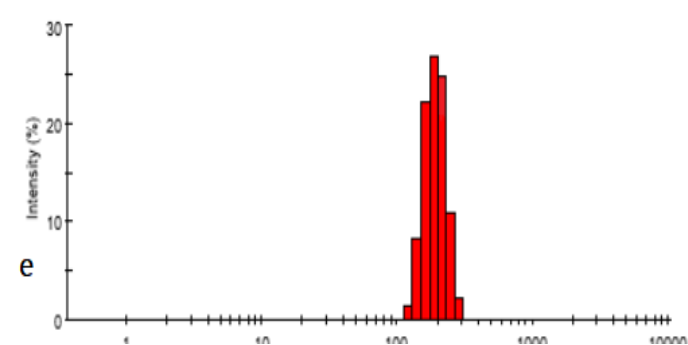

Fig. 1: Particle size and PDI of nanoparticles suspensions a) F1 b) F4 c) F7 d) F8 e) F9

Table 4: pH and viscosity of nanoparticles suspension

\begin{tabular}{lll}
\hline Formulation & $\mathbf{p H}^{*}$ & Viscosity $^{*}\left(\mathbf{x} \mathbf{1 0}^{\mathbf{- 3}} \mathbf{P a} \cdot \mathbf{s}\right)$ \\
\hline F1 & $6.14 \pm 0.244$ & $1.3 \pm 0.081$ \\
F2 & $6.32 \pm 0.089$ & $1.5 \pm 0.094$ \\
F3 & $6.29 \pm 0.253$ & $1.5 \pm 0.081$ \\
F4 & $6.18 \pm 0.045$ & $1.7 \pm 0.078$ \\
F5 & $6.41 \pm 0.093$ & $1.8 \pm 0.124$ \\
F6 & $6.25 \pm 0.054$ & $2.2 \pm 0.163$ \\
F7 & $6.18 \pm 0.052$ & $2.7 \pm 0.127$ \\
F8 & $6.36 \pm 0.033$ & $2.9 \pm 0.086$ \\
F9 & $6.57 \pm 0.029$ & $2.9 \pm 0.122$ \\
\hline
\end{tabular}

$*($ mean $\pm S D) n=3$ 


\section{Determination of $\mathbf{p H}$}

The $\mathrm{pH}$ of Enalapril maleate loaded nanoparticles suspensions were determined by using a digital $\mathrm{pH}$ meter and the results were shown in table 4 . All formulations have $\mathrm{pH}$ close to neutral (values between 6.14 and 6.57).

\section{Determination of viscosity}

The viscosity measurements were done at room temperature using a Brookfield viscometer and the results were shown in table 4 . There was an increase in the viscosity of formulations with an increase in polymer concentration.

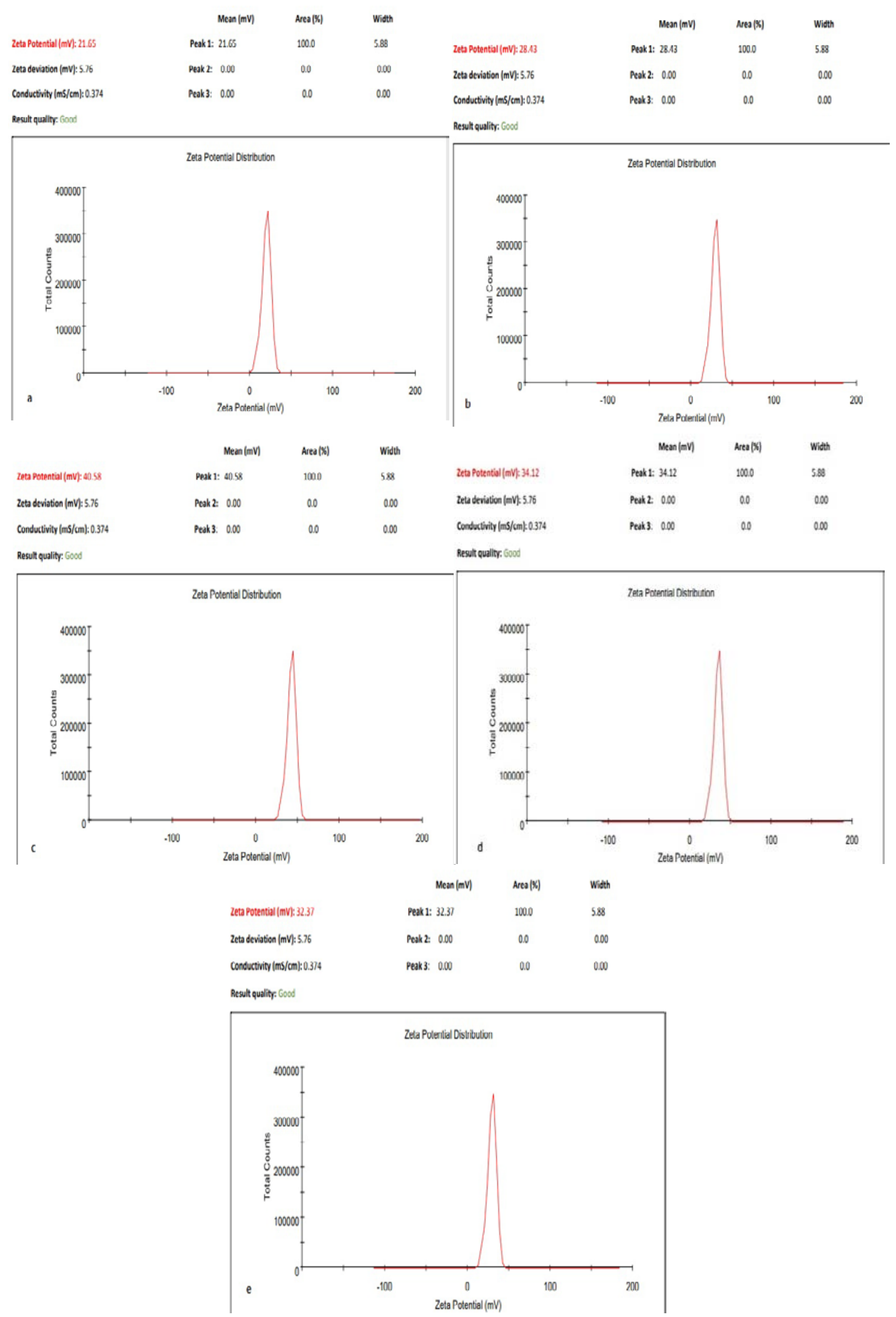

Fig. 2: Zeta potential of nanoparticles suspensions a) F1 b) F4 c) F7 d) F8 e) F9 


\section{In vitro drug release study}

The in vitro drug release study was performed for all formulations in $0.1 \mathrm{~N} \mathrm{HCl}$ for the first 1 hour and in phosphate buffer $\mathrm{pH} 6.8$ up to 12 $\mathrm{h}$ by dialysis membrane diffusion technique (fig. 3 ).

The first 3 formulations F1, F2 and F3 (drug: polymer ratio 1:50) showed approximately $5 \%$ drug release in the stomach $(0.1 \mathrm{~N} \mathrm{HCl})$ and release completed within $9 \mathrm{~h}$. In the case of the remaining 6 formulations (F4-F9), there was no release of the drug in $0.1 \mathrm{~N} \mathrm{HCl}$. This may be due to the increase in polymer concentration (ERS100).
The cumulative $\%$ drug release of F4, F5, F6, F7, F8 and F9 at 12 h were $90.1 \%, 95.4 \%, 98.2 \%, 75.3 \%, 81.2 \%$ and $83.4 \%$ respectively.

Among all the formulations, F7 shows a slow release of the drug, maybe due to greater entrapment $(79.84 \%)$ of drug within the polymeric matrix and F3 shows comparatively faster drug release due to minimum entrapment $(39.53 \%)$ of the drug. The slow release of drugs with higher entrapment efficiency could be explained based on free drug concentration on the surface of nanoparticles [24].

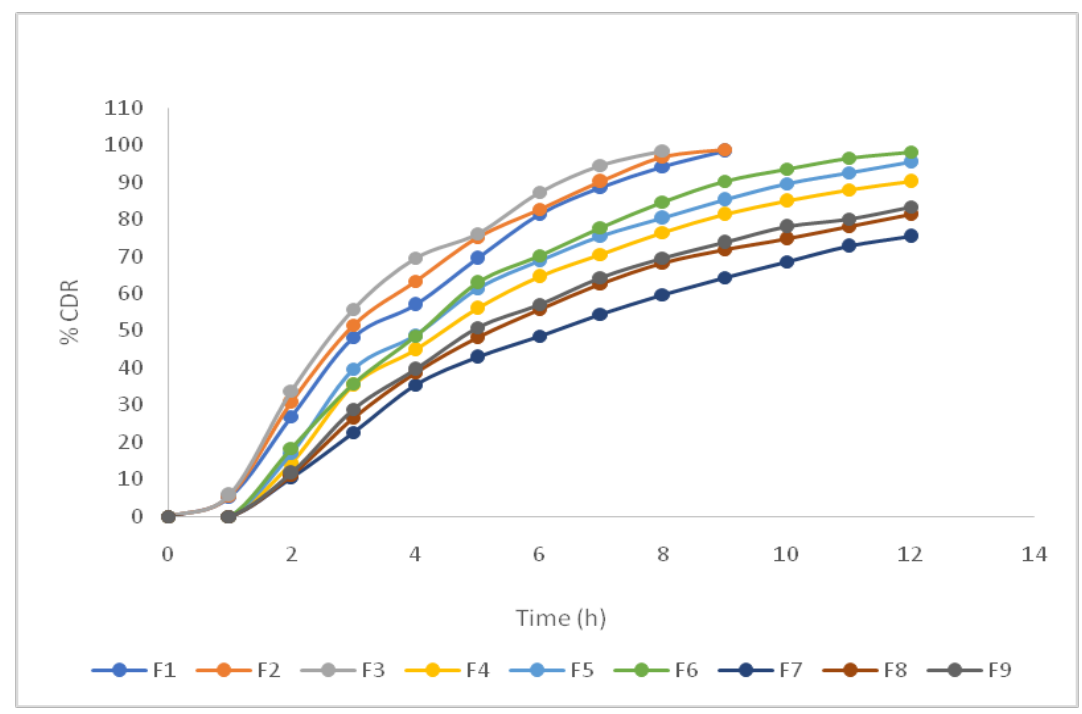

Fig. 3: \% cumulative drug release of nanoparticles suspensions, data is given as mean, $n=3$

\section{Optimization of formulations}

The entrapment efficiency, viscosity and in vitro drug release data of all the formulations were compared.

Based on entrapment efficiency, viscosity and in vitro drug release, formulation F8 was selected as an optimized formulation. F8 has entrapment efficiency-77.71\% and viscosity-2.9 x10^(-3)Pa.s. Also showed drug release of $81.2 \%$ within $12 \mathrm{~h}$, comparatively faster release than formulation F7 (entrapment efficiency-79.84\%). In the case of formulation F9, 83.4\% drug was released within $12 \mathrm{~h}$. But F9 has lower entrapment efficiency (73.12\%) compared to F8. So, formulation F8 was selected for further evaluation.

\section{Evaluation of optimized formulation}

\section{Taste evaluation}

The in vitro evaluation of taste for optimized formulation (F8) was done by the spectrophotometric method. The result was shown in table 5. The threshold bitterness concentration of Enalapril maleate is $0.107 \mathrm{mmol} / \mathrm{l}$ or $28 \mu \mathrm{g} / \mathrm{ml}$. The result showed that F8 has not attained the threshold bitterness concentration in 60 seconds. Thus, it can be concluded that the formulation has taste-masking properties.

Table 5: In vitro evaluation of taste of nanoparticles suspension

\begin{tabular}{ll}
\hline Time (second) & Amount of drug released $(\boldsymbol{\mu g} / \mathbf{m l})$ \\
\hline 60 & 13.1 \\
\hline
\end{tabular}

\section{Ex vivo permeation study}

Ex vivo intestinal permeation study of Enalapril maleate loaded nanoparticles suspension (F8) was performed by non-everted intestinal sac method using goat intestine (fig. 4 and 5).

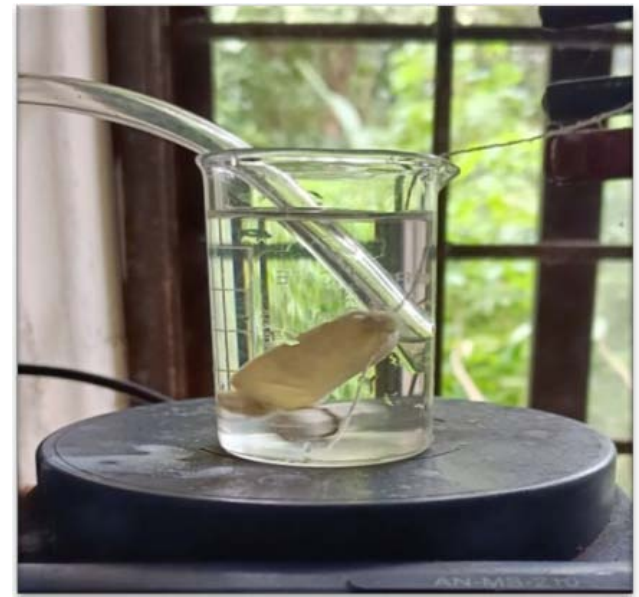

Fig. 4: Ex vivo intestinal permeation study

The formulation F8 showed $84.6 \%$ permeation through the freshly obtained goat intestine within $12 \mathrm{~h}$.

\section{Differential scanning calorimetry (DSC)}

The DSC thermograms of the drug and the nanoparticle formulation are shown in fig. 6 and fig. 7, respectively.

The DSC thermogram of the pure drug showed a sharp endothermic peak at $151.6{ }^{\circ} \mathrm{C}$, corresponding to its melting point. The DSC thermogram of the optimized formulation shows a sharp peak at $150^{\circ} \mathrm{C}$. This suggests that the characteristics of the drug were not lost due to the formulation of nanoparticles. It also suggested the absence of any drug-polymer interactions, which might have resulted in the degradation of the drug. 


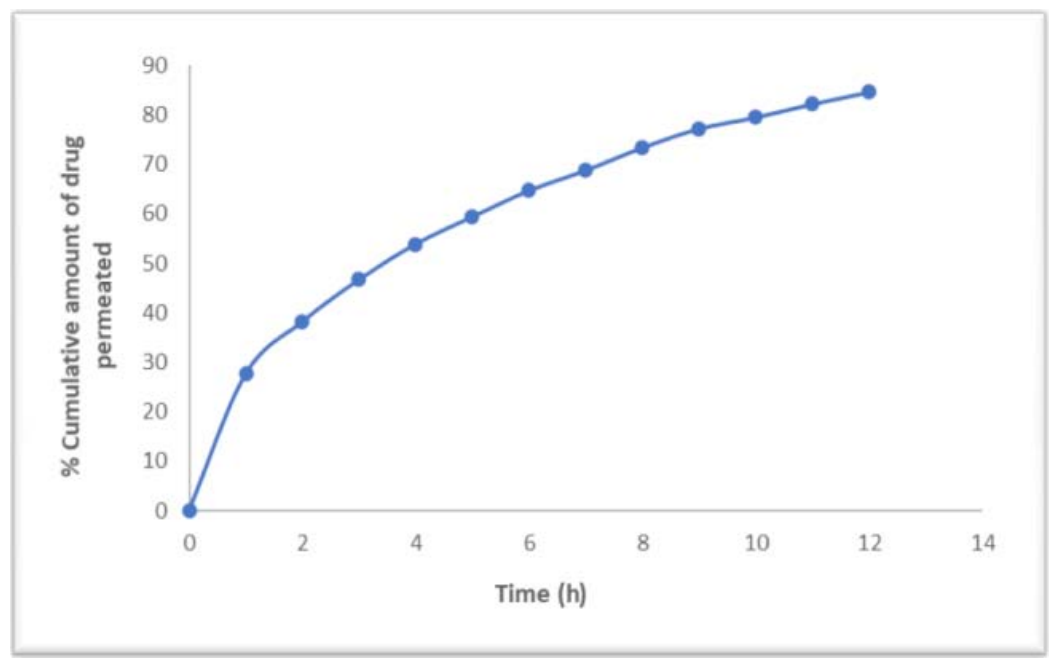

Fig. 5: Ex vivo intestinal permeation study through goat intestine

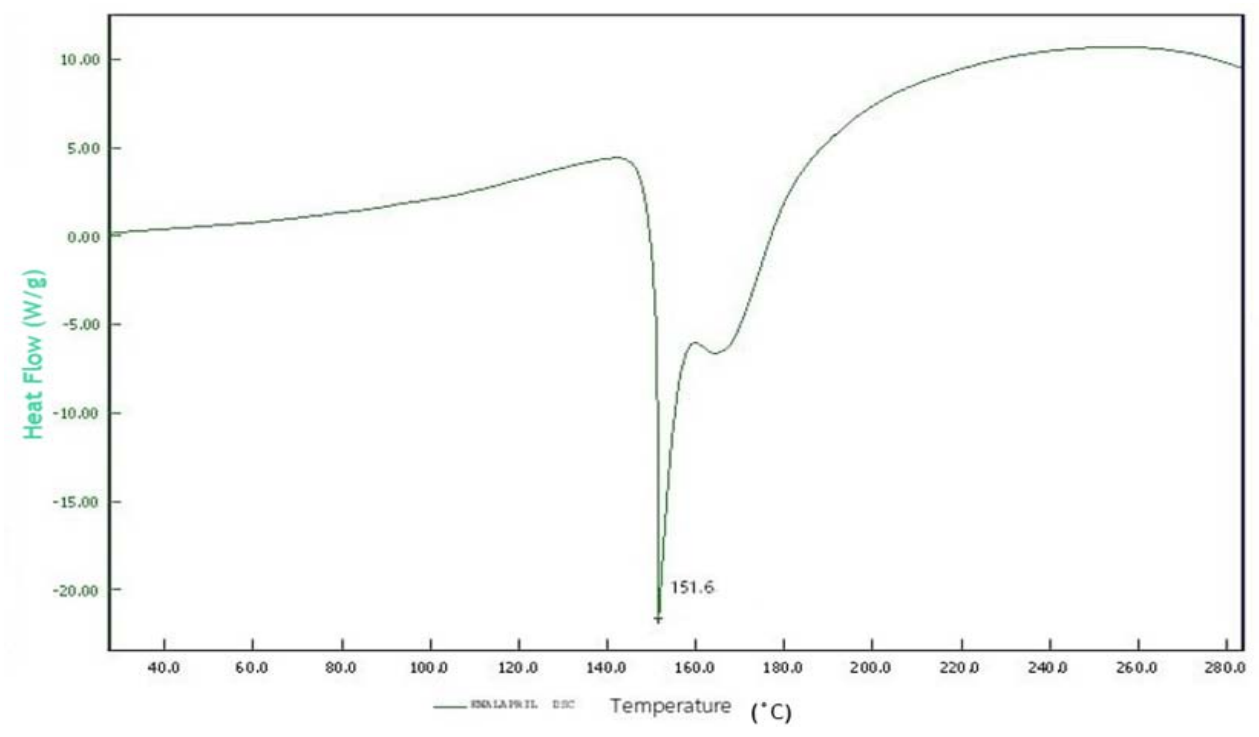

Fig. 6: DSC thermogram of EM

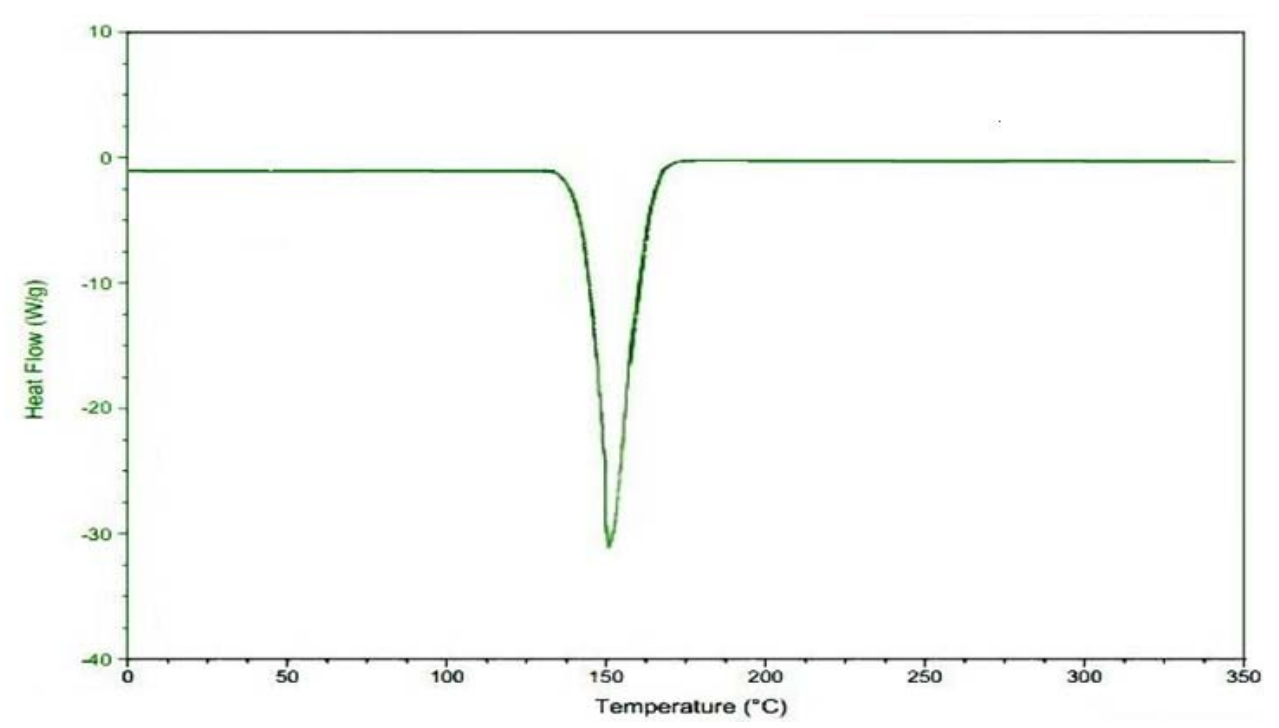

Fig. 7: DSC thermogram of EM loaded nanoparticles suspension 


\section{Scanning electron microscopy (SEM)}

The shape and surface morphology of the optimized formulation F8 were studied by Scanning electron microscopy and is shown in fig. 8 .

The result of scanning electron microscopy revealed that the nanoparticles suspension of Enalapril maleate (F8) were somewhat spherical and had a smooth surface with a particle size range of $200 \mathrm{~nm}$.

\section{In vitro drug release kinetic study}

The in vitro drug release data of formulation F8 (table 6) was fitted to various kinetic models like zero-order, first-order, Higuchi model, and Korsmeyer-Peppas model. In vitro drug permeation data was subjected to the goodness of fit by linear regression analysis according to zeroorder, first-order, Higuchi, Korsmeyer-Peppas (fig. 9) model to ascertain the mechanism of drug release. The results of linear regression data, including regression coefficient, are listed in table 7.

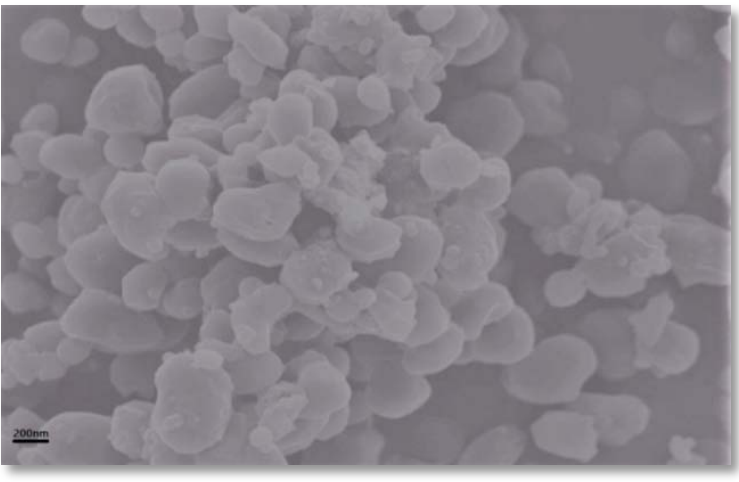

Fig. 8: SEM image of optimized nanoparticles suspension

Table 6: In vitro drug release kinetics

\begin{tabular}{|c|c|c|c|c|c|c|}
\hline S. No. & Time (h) & Log time & Square root of time & $\%$ CDR & Log \% CDR & Log \% CDR remaining \\
\hline 1 & 0 & & 0 & 0 & & 2.0000 \\
\hline 2 & 1 & 0 & 1 & 0 & & 2.0000 \\
\hline 3 & 2 & 0.301 & 1.4142 & 11.2 & 1.0492 & 1.9484 \\
\hline 4 & 3 & 0.477 & 1.7321 & 26.5 & 1.4232 & 1.8663 \\
\hline 5 & 4 & 0.602 & 2.0000 & 38.8 & 1.5888 & 1.7868 \\
\hline 6 & 5 & 0.699 & 2.2361 & 48.1 & 1.6821 & 1.7152 \\
\hline 7 & 6 & 0.778 & 2.4495 & 55.6 & 1.7451 & 1.6474 \\
\hline 8 & 7 & 0.845 & 2.6458 & 62.6 & 1.7966 & 1.5729 \\
\hline 9 & 8 & 0.903 & 2.8284 & 68.3 & 1.8344 & 1.5011 \\
\hline 10 & 9 & 0.954 & 3.0000 & 71.9 & 1.8567 & 1.4487 \\
\hline 11 & 10 & 1.000 & 3.1623 & 74.7 & 1.8733 & 1.4031 \\
\hline 12 & 11 & 1.041 & 3.3166 & 78.1 & 1.8927 & 1.3404 \\
\hline 13 & 12 & 1.079 & 3.4641 & 81.2 & 1.9096 & 1.2742 \\
\hline
\end{tabular}
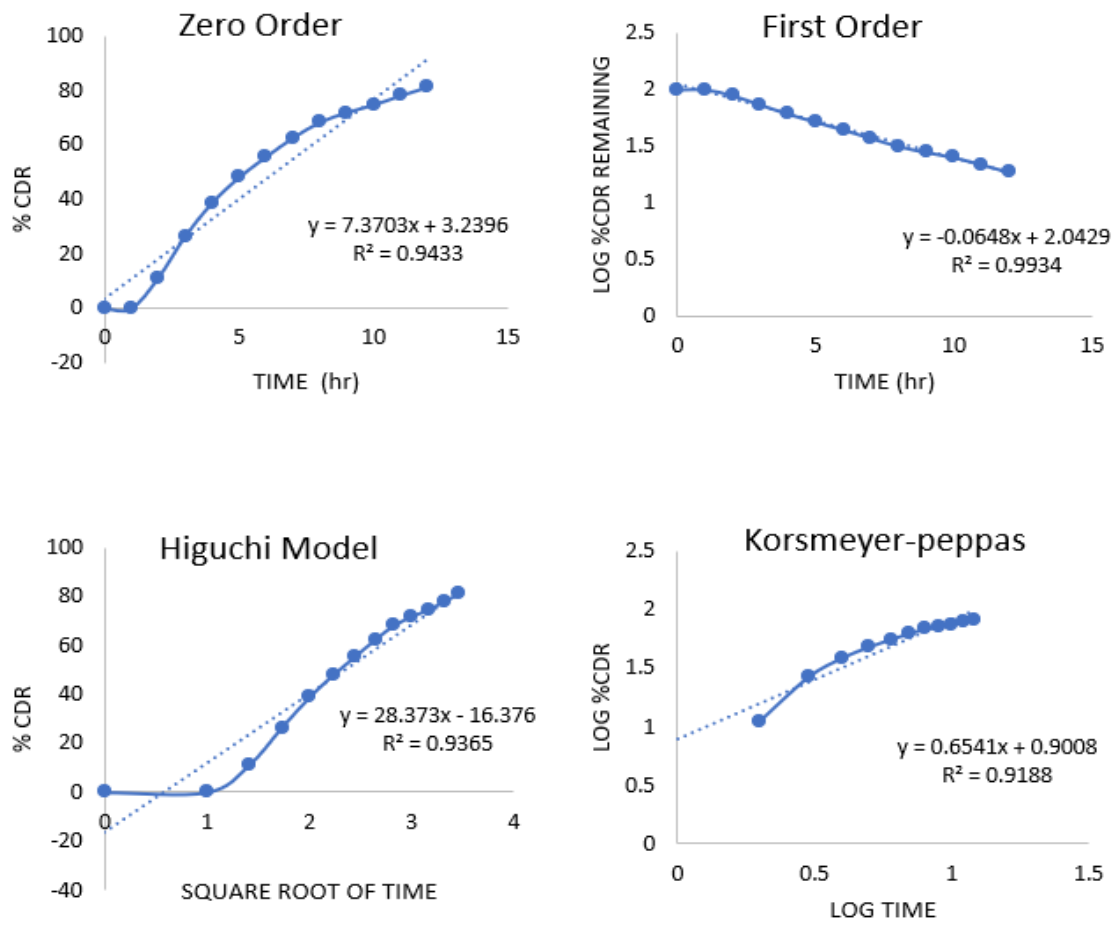

Fig. 9: Release kinetic studies

Table 7: Regression coefficients of various kinetics models

\begin{tabular}{llll}
\hline Zero order & First order & Higuchi model & Korsmeyer peppas model \\
\hline R2 & R2 & R2 & R2 \\
0.9433 & 0.9934 & 0.9365 & 0.9188 \\
\hline
\end{tabular}


The regression coefficient $\left(\mathrm{R}^{2}\right)$ obtained for first-order kinetics and zero-order kinetics was 0.9934 and 0.9433 , respectively. The results indicate that the drug release follows nearing first-order kinetics. The coefficients obtained from the Higuchi model was 0.9365, indicating diffusion played a predominant role in the drug release procedure. The slope obtained from the Korsmeyer-Peppas equation was the ' $n$ ' value and found to be 0.6541 indicated that release was by the non-fickian transport mechanism. Non-fickian transport occurs when the drug release is time-dependent and a combination of diffusion and swelling.

\section{CONCLUSION}

Enalapril maleate loaded nanoparticles suspension was successfully prepared by the nanoprecipitation technique. The prepared formulations were evaluated. Based on the parameters, entrapment efficiency, viscosity and in vitro drug release formulation F8 was selected as an optimized batch. Formulation F8 subjected to in vitro evaluation of taste, Differential Scanning Calorimetry, Scanning Electron Microscopy and ex vivo intestinal permeability study. The result of in vitro taste evaluation indicated that F8 had taste-masking properties. The DSC thermogram of formulation F8 suggests that the characteristics of the drug were not lost due to the formulation of nanoparticles. The SEM analysis revealed the spherical nature of nanoparticles. Ex vivo, intestinal permeability study, was carried out by non-everted intestinal sac method using goat intestine. The formulation showed $84.6 \%$ permeation through the freshly obtained goat intestine within $12 \mathrm{~h}$. The optimized formulation showed the highest $\mathrm{R}^{2}$ value for the first-order kinetics and the ' $\mathrm{n}$ ' value showed a non-fickian diffusion mechanism. Hence, it was concluded that nanoprecipitation was a useful method for the successful incorporation of Enalapril maleate with high entrapment efficiency. The prepared nanoparticles suspension of Enalapril maleate was found to be an effective liquid pharmaceutical dosage form for paediatric administration with taste-masking properties.

\section{ACKNOWLEDGEMENT}

The authors express sincere thanks to the College of pharmaceutical sciences, Govt. medical college Calicut, for providing the facilities to carry out this research work.

\section{FUNDING}

No funding was provided for this study.

\section{AUTHORS CONTRIBUTIONS}

All the authors have contributed equally.

\section{CONFLICTS OF INTERESTS}

The authors declare that they have no conflicts of interest.

\section{REFERENCES}

1. Ivanovska V, Rademaker CM, van Dijk L, Mantel-Teeuwisse AK. Pediatric drug formulations: a review of challenges and progress. Pediatrics. 2014;134(2):361-72. doi: 10.1542/peds.2013-3225, PMID 25022739.

2. Smeets NJL, Schreuder MF, Dalinghaus M, Male C, Lagler FB, Walsh J, Laer S, de Wildt SN. Pharmacology of enalapril in children: a review. Drug Discov Today. 2020 Aug 21;6446(20):30336-6. doi: 10.1016/j.drudis.2020.08.005, PMID 32835726.

3. Gomez HJ, Cirillo VJ, Irvin JD. Enalapril: a review of human pharmacology. Drugs. 1985;30Suppl 1:13-24. doi: 10.2165/00003495-198500301-00004, PMID 2994984.

4. Georgieva Y, Kassarova M, Kokova V, Apostolova E, Pilicheva B. Taste masking of enalapril maleate by microencapsulation in Eudragit EPO® microparticles. Pharmazie. 2020 Mar 20;75(2):61-9. doi: 10.1691/ph.2020.9123, PMID 32213236.

5. Georgieva YZ, Pilicheva BA, Kokova VY, Apostolova EG, Kassarova MI. Taste masking of enalapril maleate by the precipitation method. Folia Med (Plovdiv). 2019 Sep 30;61(3):426-34. doi: 10.3897/folmed.61.e39208, PMID 32337930.

6. Diefenthaeler HS, Bianchin MD, Marques MS, Nonnenmacher JL, Bender ET, Bender JG, Nery SF, Cichota LC, Kulkamp Guerreiro
IC. Omeprazole nanoparticles suspension: development of a stable liquid formulation with a view to pediatric administration. International Journal of Pharmaceutics. 2020 Nov 15;589. doi: 10.1016/j.ijpharm.2020.119818, PMID 119818.

7. Krieser K, Emanuelli J, Daudt RM, Bilatto S, Willig JB, Guterres SS, Pohlmann AR, Buffon A, Correa DS, Kulkamp Guerreiro IC. Taste-masked nanoparticles containing saquinavir for paediatric oral administration. Mater Sci Eng C Maer Biol Appl. 2020 Dec;117. PMID 111315.

8. Patil N, Bhaskar R, Vyavhare V, Dhadge R, Khaire V, Patil Y. Overview on methods of synthesis of nanoparticles. Int J Curr Pharm Sci. 2020 Nov 5;15(2):11-6. doi: 10.22159/ijcpr.2021v13i2.41556.

9. D’Mello SR, Das SK, Das NG. Polymeric nanoparticles for smallmolecule drugs: biodegradation of polymers and fabrication of nanoparticles. Drug Deli Nano Form Charact. 2006 Dec 16;61(3):45-52.

10. Hamid KM, Wais M, Sawant G. A review on nanoemulsions: formulation, composition, and applications. Asian J Pharm Clin Res. 2021 Apr 8;23(1):22-8. doi: 10.22159/ajpcr.2021.v14i4.40859.

11. Zielinska A, Carreiro F, Oliveira AM, Neves A, Pires B, Venkatesh DN, Durazzo A, Lucarini M, Eder P, Silva AM, Santini A, Souto EB. Polymeric nanoparticles: production, characterization, toxicology and ecotoxicology. Molecules. 2020 Jan;25(16):3731. doi: 10.3390/molecules25163731, PMID 32824172.

12. Raja MS, Venkataramana K. Formulation and evaluation of stabilized eprosartan nanosuspension. Int J App Pharm. 2020 Nov 6;12(6):83-7. doi: 10.22159/ijap.2020v12i6.39123.

13. Yellanki SK, Manoj A S, T M. Preparation and in vitro evaluation of metoprolol-loaded bovine serum albumin nanoparticles. Asian J Pharm Clin Res. 2021 Jan 5;14(1):213-7. doi: 10.22159/ajpcr.2021.v14i1.39738.

14. Senthilnathan B, Maheswaran A, Gopalasatheeskumar K, Masilamani K, Edros RZ. Formulation and evaluation of pregabalin-loaded eudragit S100 nanoparticles. IJETS. 2016 Dec 30;3(2):64-70. doi: 10.15282/ijets.6.2016.1.9.1059.

15. Balzus B, Sahle FF, Honzke S, Gerecke C, Schumacher F, Hedtrich S, Kleuser B, Bodmeier R. Formulation and ex vivo evaluation of polymeric nanoparticles for controlled delivery of corticosteroids to the skin and the corneal epithelium. Eur J Pharm Biopharm. 2017 Jun 1;115:122-30. doi: 10.1016/j.ejpb.2017.02.001, PMID 28189623.

16. Thoke SB, Gayke A, Dengale R, Patil P, Sharma Y. Review on: taste masking approaches and evaluation of taste masking. Int J Pharm Sci. 2012;4(2):1895-907.

17. Zervakis J, Graham BG, Schiffman SS. Taste effects of lingual application of cardiovascular medications. Physiol Behav. 2000 Jan 1;68(3):405-13. doi: 10.1016/s0031-9384(99)00208-5, PMID 10716552.

18. Liu W, Pan H, Zhang C, Zhao L, Zhao R, Zhu Y, Pan W. Developments in methods for measuring the intestinal absorption of nanoparticle-bound drugs. Int J Mol Sci. 2016 Jul 21;17(7):1171. doi: 10.3390/ijms17071171, PMID 27455239.

19. Punitha K, Kumar SS. Ex vivo permeability experiments in excised goat intestinal tissue and in vitro solubility enhancement of rosiglitazone by solid dispersion technique. J Pharm Resear. 2011 Jan;4(1):80-2.

20. Narade S, Pore Y. Optimization of ex vivo permeability characteristics of berberine in the presence of quercetin using 32 full factorial design. J App Pharm Sci. 2019 Jan;9(1):73-82. doi: 10.7324/JAPS.2019.90111.

21. Hina KS, Kshirsagar RV, Patil SG. Mathematical models for drug release characterization: a review. Wor J PharmSci. 2015;4(04):324-38.

22. Ramteke KH, Dighe PA, Kharat AR, Patil SV. Mathematical models of drug dissolution: a review. Sch Acad J Pharmacol. 2014;3(5):388-96.

23. Ray S, Mishra A, Mandal TK, Sa B, Chakraborty J. Optimization of the process parameters for the fabrication of a polymercoated layered double hydroxide-methotrexate nanohybrid for the possible treatment of osteosarcoma. RSC Adv. 2015;5(124):102574-92. doi: 10.1039/C5RA15859A, PMID 102574. 
24. Song X, Zhao Y, Hou S, Xu F, Zhao R, He J, Cai Z, Li Y, Chen Q. Dual agents loaded PLGA nanoparticles: the systematic study of particle size and drug entrapment efficiency. Eur J Pharm Biopharm. 2008 Jun 1;69(2):445-53. doi: 10.1016/ j.ejpb.2008.01.013, PMID 18374554.
25. Sukmawati A, Utami W, Yuliani R, Da'i M, Nafarin A. Effect of tween 80 on nanoparticle preparation of modified chitosan for targeted delivery of combination doxorubicin and curcumin analogue. IOP Conf Ser: Mater Sci Eng. 2018;311. doi: 10.1088/1757-899X/311/1/012024. 